\title{
IT GOVERNANCE IN THE REAL ESTATE INDUSTRY: A FRAMEWORK SUGGESTION
}

\author{
DOI: 10.17261/Pressacademia.2019.1165 \\ JBEF- V.8-ISS.4-2019(4)-p.215-222
}

\section{Levent Sumer}

Istinye University, Faculty of Economics, Administrative and Social Sciences, Topkapı Campus, Zeytinburnu, Istanbul, Turkey. levent.sumer@istinye.edu.tr, ORCID: 0000-0002-2160-8803

Date Received: November 5, 2019

Date Accepted: December 24, 2019

To cite this document

Sumer, Levent (2019). IT governance in the real estate industry: a framework suggestion. Journal of Business, Economics and Finance (JBEF), V.8(4), p.215-222.

Permemant link to this document: http://doi.org/10.17261/Pressacademia.2019.1165

Copyright: Published by PressAcademia and limited licenced re-use rights only.

\section{ABSTRACT}

Purpose - Information technology is the core issue that all the companies need to re-evaluate and re-organize to adapt themselves to the digital world. This study investigates the critical IT governance factors for effective and sustainable success and the growth of real estate investment companies and developing a new IT governance framework.

Methodology - The common literature about IT governance is searched and by taking into consideration of the dynamics of the industry, the conceptual framework is developed for specifically real estate industry.

Findings- The model developed is suggesting the corporate cultures, organizational structures and industry culture as critical IT governance (ITG) existence factors for the real estate industry. Effective IT tool selection and effective data flow and integration are also recommended as IT governance effectiveness parameters. Sustainable growth, asset utilization, cost-effectiveness, and business flexibility are evaluated as the positive and successful business outcomes of ITG effectiveness in the real estate industry.

Conclusion- Based on the researches made in past studies, this research seems to be the first in the literature that develops an IT governance framework for real estate investment companies in emerging economies.

Keywords: Real estate IT governance, corporate governance, sustainability, corporate culture. JEL Codes: 016, O33, L85

\section{INTRODUCTION}

Real estate and construction are important sectors in the economy, employing large amounts of capital and significant proportions of the workforce (Kummerow and Chan Lun, 2005). Since real estate investment decisions are closely related to external factors such as political stability, economic development and legal regulations, the developments of the real estate companies in developing countries such as Turkey, Russia, Indonesia seem cyclical and fragile due to the unstable political situation the countries face and negative effects on the emerging economies and the lack of sufficient legal laws and regulations currently effective. In addition to external factors, internal dynamics such as the corporate cultures, organizational structures, financial situations and the decision-making processes of the companies are important for the sustainable growth of real estate companies.

In this context, in order to carry their businesses to the next generations, the real estate investment companies in emerging economies need to take important steps such as understanding the changing market dynamics and needs, utilizing their assets efficiently, managing their resources effectively, reducing and managing their costs, increasing their flexibility to react to rapidly changing conditions, and making the right decisions to grow sustainably.

Real estate decisions depend upon the land use regulations, financial institutions, legal contracts, and cultural preferences. Most of the industry, however, still think in terms of getting insider advantages and profiting from cycles. Nevertheless, transparency and market efficiency would reduce risks and therefore reduce costs of capital and thus allow for stronger long-term growthmore projects, steadier employment, fewer bankruptcies, and milder recessions. Information technology provides the required tools for implementing such changes. Meanwhile, various applications of ICT are changing the way firms do business in various branches of the real estate industry and delivering substantial productivity gains (Kummerow and Chan Lun, 2005). 
IT governance, which is defined as a subset discipline of corporate governance, focuses on information technology (IT) and its performance and risk management. The interest in IT governance is focusing on value creation efforts for an organization's strategic objectives and managing the performance of those who are responsible for creating the value of all stakeholders better.

In this research, the major factors that verify the existence of IT governance in companies are analyzed, and by taking into consideration the nature and dynamics of the sector new determinants for both ITG existence and factors for effective, sustainable success and growth of the real estate investment companies (REICs) are suggested.

\section{LITERATURE REVIEW}

\subsection{Corporate Governance vs IT Governance}

Information Technology Governance (ITG) is commonly referred to as a subset of Corporate Governance (CG). Information Technology (IT) has been used in large organizations since the 1950s or 1960s, for internal and for external purposes. This pervasive use of technology has created a critical dependency on IT that calls for a specific focus on IT Governance. (Almeida, 2013). The term ITG was first used in academic literature in the early 1990s, although similar phenomena had been studied for some time. Since then, research has produced various definitions of ITG, leading to a lack of clarity concerning the meaning of the term. (Buchwald and Urbach, 2013). Before I go through the details of ITG, I will briefly define corporate governance in order to clearly draw the line between CG and ITG.

Corporate governance is the set of processes, customs, policies, laws, management practices and institutions affecting the way an entity is controlled and managed. It incorporates all the relationships among the many stakeholders involved and aims to organize them to meet the goals of the organization in the most effective and efficient manner possible. An effective corporate governance strategy allows an organization to manage all aspects of its business in order to meet its objectives.

On the other hand, Weill and Ross (2004) define IT governance as specifying the decision rights and accountability framework to encourage desirable behavior in the use of IT. They identify three questions that must be addressed to achieve effective IT governance: 1 . What decisions must be made to ensure effective management and use of IT? 2 . Who should make these decisions? 3. How will these decisions be made and monitored? (Diamond, 2005)

While corporate governance is concerned with board roles, board composition, board characteristics, board, and organizational structure and processes in order to develop, implement and monitor corporate strategy, similarly, but at one level below, IT governance concentrates on the structure of relationship and processes to develop, direct and control IT resources in order to achieve enterprise's goals through value-adding contributions, which account for balancing risk versus return over IT resources and its processes. (Diamond, 2005).

In literature, there are some studies that focus on the corporate governance of real estate companies. According to Bauer et. Al (2010), since the real estate investment trusts (REITs) reduce agency problems by leaving little free cash flow management, they have a good corporate governance mechanism which results in a better performance. Hartzell et.al (2006) investigated the relation between firms' investment choices and various governance mechanisms of real estate investment trusts (REITs), and they found a link between the corporate governance structures of those companies and their investment expenditures. Kohl and Schaefers (2012) investigated the effects of corporate governance mechanisms on the market valuation of publicly traded real estate companies in the UK, France, the Netherlands and Germany and the results of their analysis exhibited that corporate governance is affecting the strategic decisions of the top managers as well as investors. Hartzell et. All (2008) analyzed the impact of corporate governance structures on the public offering (IPO) date and their study showed that higher IPO valuations and better long-term performance come with stronger governance structures. Another interesting study was conducted by Piecholtz et al (2011) which analyzed the relation between corporate governance and the performance of listed property companies in the U.S. by evaluating the before and after global economic crisis, and their results exhibited that while the performance of REITs was affected from the structure of the corporate governance after the crisis, the firm-level corporate governance did not affect the performance of equity real estate investments before the crisis.

\subsection{Need for IT Governance}

Focusing on avoiding any type of risk and uncertain situations is critical for the real estate industry. Thus, implementing IT governance is vital for organizations in order to manage and mitigate risks (Saetang and Haider, 2014). Weill and Ross (2004) exhibited at least a 20 percent better return on IT investment when effective IT governance is in place. Companies need ITG in order to, reduce the cost of day-to-day operations, improve overall operational efficiency and consistency, free more resources 
for strategic initiatives that improve competitiveness, choose those initiatives far more wisely, working on the right things, not the wrong things, bring those initiatives to market faster with less risk and bring IT into close alignment with business priorities

A company needs and IT governance for the reasons mentioned above, but what should IT governance cover to be more effective? National Computer Center published IT Governance, Developing a Successful Governing Strategy-Best Practice Guide for Decision Makers in IT in 2005. According to this guide, IT Governance is defined as an evolving process that is not just an IT issue or only of interest to the IT function. In its broadest sense, it is a part of the overall governance of an entity, but with a specific focus on improving the management and control of Information Technology for the benefit of the primary stakeholders. Ultimately it is the responsibility of the Board of Directors to ensure that IT along with other critical activities are adequately governed. Although the principles are not new, actual implementation requires new thinking because of the special nature of IT.

IT Governance spans the culture, organization, policy, and practices that provide for IT management and control across five key areas:

Strategic Alignment - Provide for the strategic direction of IT and the alignment of IT and the business with respect to services and projects. Value Delivery - Confirm that the IT/Business organization is designed to drive maximum business value from IT. Oversee the delivery of value by IT to the business and assess ROI. Risk Management - Ascertain that processes are in place to ensure that risks have been adequately managed. Include an assessment of the risk aspects of IT investments. Resource Management - Provide high-level direction for sourcing and use of IT resources. Oversee the aggregate funding of IT at the enterprise level. Ensure there is adequate IT capability and infrastructure to support current and expected future business requirements. Performance Measurement - Verify strategic compliance, i.e. achievement of strategic IT objectives. Review the measurement of IT performance and the contribution of IT to the business (i.e. delivery of promised business value).

IT Governance is not a one-time exercise or something achieved by a mandate or setting of rules. It requires a commitment from the top of the organization to instill a better way of dealing with the management and control of IT. IT Governance is an ongoing activity that requires a continuous improvement mentality and responsiveness to the fast-changing IT environment. IT Governance can be integrated within a wider Enterprise Governance approach which supports the increasing legal and regulatory requirements of Corporate Governance.

The National Computer Center Guide (2005) focuses on 12 key topics selected by the group because of their importance to effective IT governance:

The business case - because the organization needs to understand the value proposition,

- Performance measurement - to answer the question "Is the ship "on course"?",

- Implementation roadmap - to draw the path to follow,

- Communications - to explain the objectives and change the culture,

- Capability assessment - to find out the true current state of IT governance,

- Risk management - to find out the existing risks and to make sure they are dealt with,

- Supplier governance - to include the external parties which play a big role,

- IT and audit working together - to co-operate for a common goal,

- Information security - use it as a key topic in today's networked environment,

- Legal and regulatory aspects -because compliance is a global concern,

- Architectures - for effective technical solutions

- Managing investments - to ensure that value is delivered and benefits realized.

Those key topics or their derivatives were evaluated in different studies. On the basis of conceptual considerations, Guldentops (2004) presents five key success factors for IT control and governance focused on establishing appropriate IT structures and processes, as well as aligning business and IT in strategy and operations. Weill (2004) suggested eight critical success factors when assessing and implementing ITG. Transparency of the IT decisions, the simplicity of the governance arrangements and whether the incentive and reward systems are aligned are some of those factors. According to Ali and Green (2005), the significant positive relationships between ITG effectiveness and ITG mechanisms are; the IT strategy committee, senior management involvement, a culture of compliance and the corporate communication systems. Nfuka and Rusu (2010) analyzed the critical success factors for effective ITG in Tanzanian public sector organizations and found 11 factors and tested them in 2011. Some of those factors are; IT leadership, senior management support, IT/Business communication partnership, key stakeholder engagement, alignment of IT and corporate strategy, consolidation of IT structures, well-communicated IT strategies and policies, defining and tracking of benefits. They classified these factors under 4 main categories: Strategic 
Alignment, Value Delivery/Risk Management, Resource Management, and Performance Management, as categorized in the Best Practice Guide for Decision Makers published by National Computer Center.

Buchwald and Urbach (2013), categorized comprehensibility and adequateness of regulations, persuasive of communication, top management commitment, financial and HR support, integration of business and IT perspectives and IT staff's business orientation as IT governance success determinants, increase in transparency and business/IT alignment as impact factors and increase in efficiency as the goal factor.

\subsection{The Framework Developed}

The size, the focus area and the location of the company are the major factors that shape the organizational structures of real estate investment companies. Some small companies may not need some of the departments, yet in some companies, some departments may be merged or even separated. A real estate company organization should be structured by including the following departments; a strategic planning department where long-terms strategies are set and the road map is prepared, a real estate development department where the projects to invest are selected and the feasibility studies are conducted, a project development department where detailed designs are developed, a construction project management department where the projects are professionally managed in accordance with the international project management standards, a projects control department where the progress of the projects together with the comparison of the planned and actual works are monitored, an asset management department, where all the assets are managed by following standard company rules and procedures. Accounting and finance, sales and marketing, leasing, corporate communication, risk management and internal audit, investor relations, human resources, legal affairs, administrative affairs and information technology are the other major departments a large size real estate investment company needs to have.

Among those departments, there are important decisions that are directly or indirectly related to IT governance and processes. Land selections, alternative feasibility studies, go/no-do decisions, bidding strategies, procurement strategies, contracts and document management, buy-rent decisions, stock and asset management, planning, time and cost control, progress payment control, payment audit, risk analysis, payment tracking, invoicing, cost-income analysis, customer relations, occupancy and vacancy rates, investor relations, annual reports, investor presentations, press relations and internal communications are the main issues that IT governance and processes affect.

The internal and multidisciplinary relations of those departments are very important success factors of real estate investment companies. The more data is transferred among departments on time and accurately, the more companies have control over business issues as well as have strong decision-making processes.

The major IT success and effectiveness factors for IT governance studied in previous researches were evaluated as IT governance existence factors in REIC's, because there is not any previous study that has tested those factors yet in the real estate industry. In addition to those factors, three new factors added by taking into consideration the specific conditions of the industry and classified below:

- $\quad$ Strategic Alignment

- Value Delivery

- $\quad$ Risk Management

- $\quad$ Resource Management

- Performance Measurement

- Industry Culture (Market Expectations) - newly suggested

- $\quad$ Corporate Culture (Decision-Making Processes) - newly suggested

- Organizational Structure (Governance Archetypes) - newly suggested

Figure 1 shows the parameters of the IT governance existence, together with the newly suggested factors in the model proposed. The real estate industry is different from manufacturing industries because of the uniqueness of each project and it is affected by many external conditions such as politics, economic conditions, legal regulations, environmental and soil conditions and even the historical background of the cities. These conditions push REIC's to shape their corporate governance as well as their IT governance. The rules, regulations, and laws related to the industry can be classified under this factor. 
Corporate culture is another important parameter that affects IT governance in a real estate company because the institutionalization level of the sector is far behind the other industries and the decision-making processes are mostly dependent on the owner-boss of the company which directly affects the IT governance processes and procedures. Top management participation, commitment, support, and contribution can be listed under this parameter.

The third newly suggested factor for IT governance existence is organizational structure, which is focused on the governance archetypes defined by Weill and Ross (2004). The existence of the IT steering committee, the HR support, and employee fit, financial support can be categorized under this factor.

Figure 1: The IT Governance Existence Parameters (The National Computer Center Guide (2005), 3 Newly Parameters Suggested

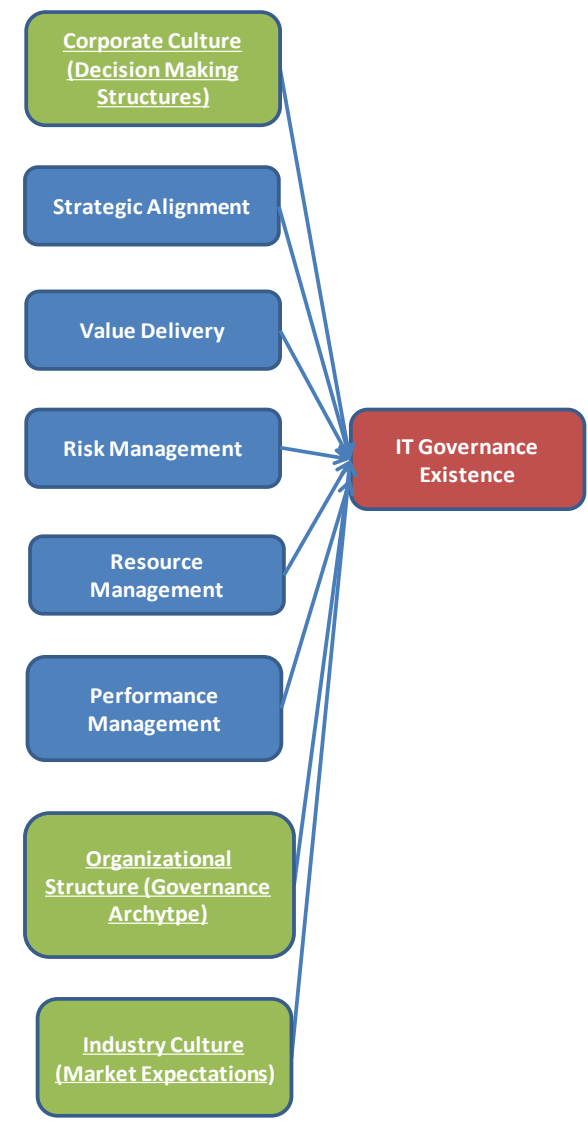

After discussing the parameters of IT governance existence, it is critical to find the way how to reach ITG effectiveness. In that context, effective data flow and integration and effective tool selection are suggested as shown in Figure 2. Even though the companies have all the required IT governance processes and procedures, ITG won't be effective if they do not select the appropriate IT tools that allow the departments mentioned above to have a smooth and effective data flow and integration, because the success of real estate companies is directly linked to having the right data in the right time to make the right decision. The question is how can we measure the ITG effectiveness in the real estate industry? What are the outcomes of effective IT governance? The selection of effective IT tools and effective data flow and integration should have positive consequences. Sustainable growth helps companies to survive, make profits and carry themselves to future generations successfully. Asset utilization helps companies to use the right asset at the right time and in the right area. Cost-Effectiveness helps them to manage and control their costs and as a result their profits. Business flexibility which enables them to react positively against the changing market and industry conditions can be listed as the main consequences. (Weill and Ross (2004)) 
Figure 2: IT Governance Effectiveness Parameters

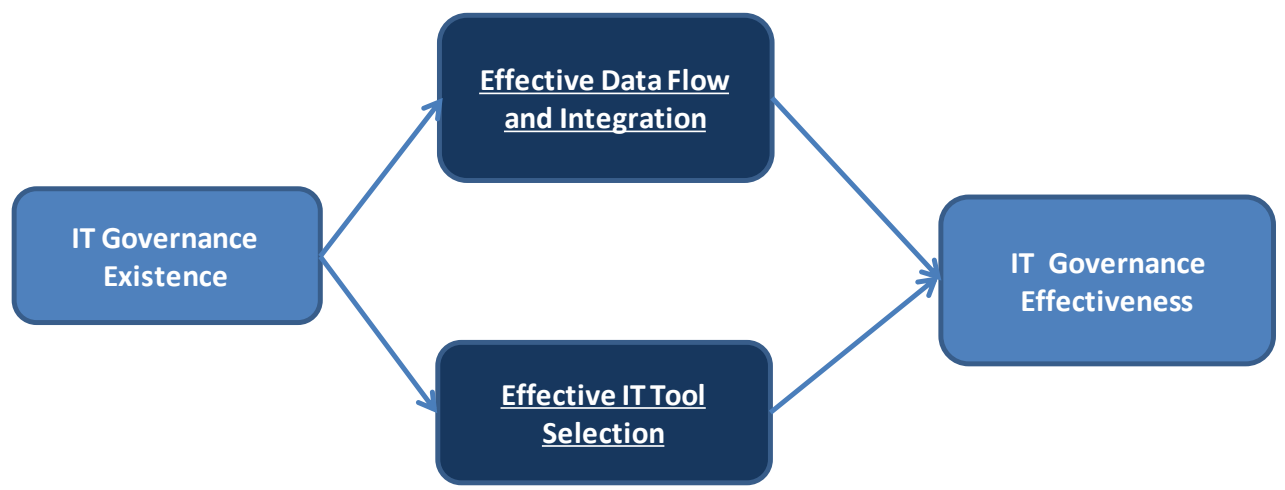

\section{DISCUSSIONS}

\subsection{IT Governance Existence}

In this study, the corporate culture is considered as decision-making structure and evaluated as an important indicator for ITG existence, but because of the nature of the industry which is far from making decisions through IT steering committees, the company owner based corporate culture of the RIEC's may negatively affect the ITG existence. The more professional the companies become, the more corporate culture may affect the ITG positively.

The organizational structure is discussed as governance archetypes and was considered as an important parameter for ITG existence but since the institutional level of the industry is far below the other industries, as in the corporate culture case, the ITG existence may negatively be affected from the organizational structure.

The culture of the real estate industry which is one of the largest industries in emerging countries is taken as a market expectation in the study and its current and future perspective seems to have a positive effect on ITG existence in the real estate industry.

Strategic alignment, value delivery, risk management, resource management, performance measurement parameters where the National Computer Center Guide (2005) suggests for the ITG existence are accepted as the having a positive outcome for real estate industry, yet the real effects of these factors are also be needed to be tested together with the newly introduced factors.

\subsection{IT Governance Effectiveness}

Effective IS/IT governance needs to provide a mechanism that enables IS/IT managers and suppliers to develop integrated business and IS/IT plans. (Kakabedse and Kakabedse, 2001). There are many phases in the real estate industry that include land selection, design development, construction, and post-construction. In each phase, there is important data to be transferred from one department to another one. The more companies have accurate and integrated data, the more they have effectiveness in their governance and decision processes.

\subsection{Business Outcomes}

All the IT governance existence and effectiveness have one purpose: Successful business outcomes. These outcomes are categorized as sustainable growth, asset utilization, cost-effectiveness and business flexibility by Weill and Ross (2004).

There is a hard competition in the real estate markets in developing countries, and there are many companies that fail due to wrong investment decisions, lack of cost control and management, inefficient resource and asset management. IT effectiveness helps the companies to track their assets and resources more effective, through efficient data flow and integration, the 
companies may shape their policies and reactions to the dynamic conditions of the market and will be one step further compared to other companies which do not have such effective IT governances.

\section{CONCLUSION}

For many organizations, Information Technology (IT) enabled business initiatives and IT infrastructures constitute major investments that, if not managed properly, may impair rather than enhance the organization's competitive position. (Bowen et al. 2007)

In the past literature, there are many studies that focused on generally on IT governance success and effectiveness. There are also some researches on ITG in developing countries such as the Nfuku and Rusu made in 2010 and 2011, but unfortunately, there are very few studies that examine the information systems in real estate industry, yet there are no published researches that study the IT Governance effectiveness of real estate investment companies in developing countries.

For this reason, in this study, the IT governance existence and effectiveness factors which may lead the REIC's in emerging economies to successful business operations are studied and IT governance as a subset discipline of corporate governance is evaluated and the main parameters that test the existence of IT governance in companies were investigated. By taking into consideration the nature and dynamics of the sector, new determinants for effective, sustainable success and growth of the real estate investment companies (REIC's) were suggested.

In this study, strategic alignment, value delivery, risk management, resource management and performance measurement which was evaluated as ITG success factors in previous studies are considered as ITG existence parameters, because their successes have not been tested for the real estate investment companies yet. Even though they are not tested in any previous studies these first five factors were accepted as verified IT governance existence factors in the real estate industry, so these five factors should also be tested in further studies whether they verify the ITG existence or not. Moreover, the two-parameter that is suggested for ITG effectiveness; effective IT tool selection and effective data flow and integration, should be examined in detail, and the possible tools and programs may be suggested. The organizational structures of the real estate companies and their background before being established as REIC's should also be examined and the size of the companies should also be taken into consideration as a factor while studying the ITG effectiveness.

\section{REFERENCES}

Almeida R.S. (2013). Implementing IT governance, Master Thesis in Information Systems and Computer Engineering, Tecnico Lisboa.

Bauer R., Eicholtz P., Kok N., (2010). Corporate governance and performance: The REIT effect, Real Estate Economics, 38 (1): 1-29. DOI: 10.1111/j.1540-6229.2009.00252.x

Bowen P. L., Cheung M., Rohde F.H. (2007). Enhancing IT governance practices: A model and case study of an organization's efforts, International Journal of Accounting Information Systems, 8: 191-221. DOI:10.1016/j.accinf.2007.07.002

Buchwald A, Urbach N. (2013). Understanding IT governance success and its impact: Result from an interview study, Proceedings of the 21st European Conference on Information Systems (ECIS 2013), Utrecht, Niederlande, Juni 5-8, 2013

Diamond L. (2005). IT Governance: How Top Performers Manage IT Decision Rights for Superior Results, International Journal of Electronic Government Research-Book Review, 1(4): 63-67

Eicholtz P., Kok N., Yonder E. (2019, December 7), Real estate, governance, and the global economic crisis, Retrieved from https://sustainablefinance.nl/upload/researches/Eichholtz-et-al_Real-Estate-Governance-and-the-Global-Economic-Crisis.pdf

Hartzell J. C., Sun L., Titman S., (2006). The effect of corporate governance on investment: Evidence from real estate investment trusts, Real Estate Economics, 34(3): 343-376. https://doi.org/10.1111/j.1540-6229.2006.00170.x

Hartzell, J.C., Kallberg J.G., Liu C.H., (2008). The role of corporate governance in initial public offerings: Evidence from real estate investment trusts, The Journal of Law and Economics, 51(3): 539-562.

Guldentops E, (2019, December 7), Key success factors for implementing IT governance: Let's not wait for regulators to tell us what to do, Information Systems Audit and Control Association, Retrieved from https://www.isaca.org.

Kakabedse N, Kakabedse A, (2001). IS/IT governance: Need for an integrated model, Corporate Governance 1(4): 9-11 
Kohl, N., Schaefers, W. (2012), Corporate governance and market valuation of publicly traded real estate companies: Evidence from Europe, The Journal of Real Estate Finance and Economics, 44(3): 362-393. DOI: 10.1007/s11146-010-9236-5

Kummerow, M, Chan Lun J. (2005) Information and Communication Technology in the Real Estate Industry: Productivity, Industry Structure and Market Efficiency, Telecommunications Policy 29 173-190

Nfuka N., Rusu, L, (2011). The Effect of critical success factors on IT governance performance, Industrial Management \& Data Systems, 111(9): 1418-1448. DOI: 10.1108/02635571111182773

Nfuka N., Rusu, L, (2010). Critical success factors for effective IT governance in the public sector organisations in a developing country: The case of Tanzania, 18th European Conference on Information Systems

Saetang S., Haider A. (2014). IT governance, risk management and value delivery in construction organizations: Literature review analysis, Proceedings of the 17th International Symposium on Advancement of Construction Management and Real Estate.

Weill P, Ross J. (2019, December 7). IT governance on one page, Retrieved from

https://cisr.mit.edu/blog/documents/2004/11/30/mit_cisrwp349_itgovononepage.pdf/ 